\title{
EXAFS in situ: The effect of bromide on Pd during the catalytic direct synthesis of hydrogen peroxide
}

\author{
P. Centomo ${ }^{\mathrm{a}, *}$, C. Meneghini ${ }^{\mathrm{b}, \mathrm{c}}$, S. Sterchele ${ }^{\mathrm{a}, \mathrm{d}}$, A. Trapananti $^{\mathrm{e}}$, G. Aquilanti $^{\mathrm{f}}$, M. Zecca $^{\mathrm{a}}$ \\ a Dipartimento di Scienze Chimiche, Università degli Studi di Padova, 35131 Padova, Italy \\ b Dipartimento di Scienze, Università degli Studi Roma TRE, Roma, Italy \\ ${ }^{\mathrm{c}}$ CNR-TASC, c/o CRG-GILDA (ESRF), Grenoble, France \\ d Industrial Chemistry and Reaction Engineering, Process Chemistry Center (PCC), Department of Chemical Engineering, Åbo Akademi University, \\ FI-20500 Turku/Åbo, Finland \\ e CNR-IOM-OGG, c/o European Synchrotron Radiation Facility, 71, avenue des Martyrs, 38000 Grenoble, France \\ f Sincrotrone Trieste, ELETTRA, 34012 Basovizza, TS, Italy
}

\section{A R T I C L E I N F O}

\section{Article history:}

Received 16 May 2014

Received in revised form 6 October 2014

Accepted 7 October 2014

Available online $\mathrm{xxx}$

In memory of the late Professor Benedetto Corain (July 8th 1941 - September 24th 2014), passionate chemist and teacher

\section{Keywords:}

Palladium

Hydrogen peroxide

Direct synthesis

EXAFS

In situ

\begin{abstract}
A B S T R A C T
The direct synthesis of hydrogen peroxide is catalyzed by palladium catalysts supported over different solids. With the aid of a suitable plug-flow reaction cell, we carried out a preliminary X-ray absorption fine structure spectroscopy (EXAFS) characterization of a palladium catalyst supported on the commercial resin K2621 under reaction conditions (in situ). Whereas the catalyst, which in the dry catalyst presents metal Pd and PdO when fresh, is practically unaffected by the reaction medium (methanol) or by the reaction mixture $\left(\mathrm{CO}_{2} / \mathrm{H}_{2} / \mathrm{O}_{2}, 86 / 10 / 4, \mathrm{v} / \mathrm{v}\right)$ it undergoes an apparent reduction of part of PdO to metal $\mathrm{Pd}$ and some metal leaching during the reaction in the presence of bromide ions. These findings suggest the role of bromide ions as enhancers of the selectivity of palladium catalysts in the direct synthesis of hydrogen peroxide could not be limited to the selective blocking of the sites responsible for the undesired formation of water, but could also entail phase modifications of the active metal.
\end{abstract}

(C) 2014 Elsevier B.V. All rights reserved.

\section{Introduction}

Heterogeneous catalysts supported on commercial ionexchange resins for the direct synthesis (DS) of hydrogen peroxide from the elements, $\mathrm{H}_{2}+\mathrm{O}_{2} \rightarrow \mathrm{H}_{2} \mathrm{O}_{2}$, has been under investigation for several years [1-5].

This reaction is of interest to both industry [6-11] and the academia [12-24] for the small scale, on-site and on-demand production of this commodity, for which the anthraquinone autooxidation (AO) process is not convenient [12]. The key issue in this reaction is the selectivity towards $\mathrm{H}_{2} \mathrm{O}_{2}$, because the active Pd or bimetallic Pd-Au or Pd-Pt catalysts also promote the formation of water, that is the thermodynamically favoured product.

\footnotetext{
* Corresponding author. Tel.: +39 0498275206.

E-mail addresses: paolo.centomo@unipd.it (P. Centomo) carlo.meneghini@fis.uniromatre.it (C. Meneghini), ssterche@abo.fi (S. Sterchele), angela.trapananti@esrf.fr (A. Trapananti),giuliana.aquilanti@elettra.eu (G. Aquilanti).
}

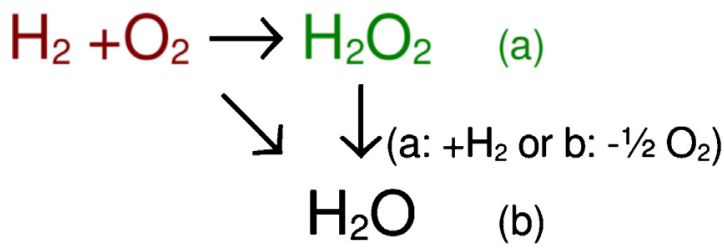

The addition of gold to the palladium catalysts [25] or the addition of halide ions $\left(\mathrm{Cl}^{-}, \mathrm{Br}^{-}\right)$to the reaction mixture, especially in combination with mineral acids [13], are the most effective ways to enhance the selectivity reported so far. While enhancing the selectivity, the halide ions decrease the reaction rate [13]. Purportedly they avoid the dissociative chemisorption of dioxygen by blocking preferentially the sites where it takes place $[13,25]$. This hypothesis is supported by theoretical models obtained from DFT calculations [26], but the mechanism is still unclear and sound direct evidence on the nature of their action not achieved yet.

To the best of our knowledge, no information on the role played by halide ions as DS promoters has been gathered in situ and reported so far. This kind of information is highly desirable [27] and 
in this context we have recently reported on the implementation of a cell for the XAFS analysis of solid catalysts under gas-liquid-solid conditions [28].

The XAFS (X-ray absorption fine structure spectroscopy) is a well ascribed $[29,30]$ chemically selective technique to probe the chemical nature of the absorber (valence state) its coordination chemistry, and the local atomic structure around it. The XAFS signal is constituted by the fine oscillations that can be observed on the atomic absorption coefficient of not isolated atoms. The scattering theory describes these features as caused by the interference between the photoelectron waves outgoing from the absorber and scattered by the surrounding atomic potentials [31]. The XAFS signal is traditionally distinguished in two regions: the near edge (XANES: X-ray absorption near edge structure) and the extended (EXAFS: extended X-ray absorption fine structure) regions. In the EXAFS region a relatively simple and well ascribed formalism allows to understand the local atomic structure around the average absorber in the sample as a combination of coordination shells whose parameters (coordination numbers, coordination distances and disorder factors can be accurately determined by least square refinement procedures [31-33]. The theory required for ab-initio modelling the XANES features is generally complex because they are affected by the finest details of interatomic potentials and full multiple scattering effects take place [31]. However the XANES region is dense of structural and electronic information that can be often understood comparing the data of reference compound [30].

We report herein on the in situ XAFS investigation with this cell of a nanostructured Pd catalyst for the DS working in the presence of sodium bromide. In view of our long-standing interest into polymer-supported metal catalysts [34-38] and into their application to DS [5], this preliminary investigation was focused on a monometallic Pd catalyst supported on the commercial ionexchange resin Lewatit K2621. The experiments performed with the in situ XAFS cell, have been carried out under atmospheric pressure. Although this condition could not be optimal for practical applications, valuable information can be anyway collected as shown by the achievements of Lunsford's and Strukul's groups in the field $[19,20,23]$.

\section{Experimental}

Lewatit K2621 (sulfonated polystyrene-divinylbenzene macroreticular ion-exchange resin; exchange capacity $=1.92 \mathrm{mmol} / \mathrm{g}$ ) was kindly provided by Lanxess. All the reagents and the materials were used as received from Sigma-Aldrich.

The preparation of the catalyst $\mathrm{Pd} / \mathrm{K} 2621 \mathrm{f}$ is described in ref. [4]. The detailed description of the catalytic cell for in situ XAFS measurements is reported in ref. [28]. In a typical experiment, an aqueous solutions of $\left[\mathrm{Pd}\left(\mathrm{NH}_{3}\right)_{4}\right] \mathrm{SO}_{4}(0.0256 \mathrm{~g}, 0.188 \mathrm{mmol}$, corresponding to $1 \% \mathrm{Pd}(\mathrm{w} / \mathrm{w})$, in the final catalysts) was added to a suspension of $1.0104 \mathrm{~g}$ of $\mathrm{K} 2621 \mathrm{in} 10 \mathrm{ml}$ of distilled water, after swelling for $2 \mathrm{~h}$. The suspension was let to react overnight on a swirling plate. The solid was recovered by vacuum filtration, carefully washed with distilled water $(3 \times 10 \mathrm{ml})$ on the gooch filter and dried overnight at $110^{\circ} \mathrm{C}$. The filtrate was combined with the washing liquor and analyzed with ICP-MS for the quantitative determination of the unreacted metal. After the ion-exchange, the residual amount of Pd in the mother liquor was less than $0.1 \%$ of its starting amounts. Consequently, the uptake of palladium was complete and the experimental metal loading practically corresponds to the nominal one for each sample.

The beige (very light brown-yellow) solid was suspended in $50 \mathrm{ml}$ of $37 \%$ aqueous formaldehyde solution and heated up to reflux condition with an oil bath for $3 \mathrm{~h}$. The black product was recovered by vacuum filtration and carefully washed with distilled water $(3 \times 10 \mathrm{ml})$. The material was dried in oven at $110^{\circ} \mathrm{C}$ overnight.

XAFS measurements at Pd K-edge $(24,350 \mathrm{eV})$ in transmission geometry have been collected at ELETTRA-XAFS [39] and ESRFBM08 [40] beamlines. The structural EXAFS (extended-XAFS) signal has been extracted and quantitatively analyzed using ESTRA and Fitexa programs, respectively [41].

The catalyst was characterized by EXAFS at room temperature in the dry state (polyvinylpirrolydone pellet), in the methanolswollen state, with the alcohol flowing through the catalyst placed inside the measurement cell after swelling with methanol, and under reaction conditions, respectively with or without $10 \mathrm{ppm}$ of $\mathrm{NaBr}$ dissolved in methanol. For the latter experiment a mixture of methanol (or a $10 \mathrm{ppm} \mathrm{NaBr}$ solution in methanol), pre-saturated with $\mathrm{CO}_{2}, \mathrm{H}_{2}$ and $\mathrm{O}_{2}$, of $\mathrm{H}_{2}$ and of $\mathrm{O}_{2}$ were continuously let to flow through the catalyst bed inside the measurement cell. As described in Ref. [28] each gas was separately fed with a dedicated syringe at atmospheric pressure at the desired flow rates. Flow rates $\left(\mathrm{CO}_{2}: 1.72 \mathrm{ml} / \mathrm{min}, \mathrm{O}_{2}: 0.20 \mathrm{ml} / \mathrm{min}, \mathrm{H}_{2}: 0.08 \mathrm{ml} / \mathrm{min}\right.$; $\mathrm{CO}_{2} / \mathrm{H}_{2} / \mathrm{O}_{2}=86 / 10 / 4, \mathrm{v} / \mathrm{v}$ ) were set as to keep the gas mixture out of the explosive range [42]. The liquid was fed using a peristaltic pump.

The same procedure has been employed also for the off-line catalytic runs for the quantitative analysis of $\mathrm{H}_{2} \mathrm{O}_{2}$ and the concentration of $\mathrm{H}_{2} \mathrm{O}_{2}$ has been measured by iodometric titration.

\section{Results and discussion}

In this work we investigated with EXAFS in situ a palladium catalyst obtained during a previous investigation of ours [4] under halogen-free conditions to prevent the accidental retention of halide ions. For this purpose $\left[\mathrm{Pd}\left(\mathrm{NH}_{3}\right)_{4}\right]^{2+}$ was used as the metal precursor and ion-exchanged for $\mathrm{H}^{+}$in the resin Lewatit $\mathrm{K} 2621$. The immobilized metal complex was the reduced with $37 \%$ aqueous formaldehyde at reflux.

Since the goal of this investigation was to simply check the reliability of the apparatus for the characterization in situ of the catalysts for the DS reaction, we did not attempt any quantitative estimate of the production of $\mathrm{H}_{2} \mathrm{O}_{2}$ and of the selectivity towards it during the XAFS measurements. The production of $\mathrm{H}_{2} \mathrm{O}_{2}$ was only qualitatively shown upon the addition of an acidic solution of $\mathrm{TiOSO}_{4}$ [43] to samples of the liquid phase collected at the cell outlet. However, representative off-line experiments with the same experimental set-up, carried out in our laboratory, showed that under these conditions the concentration of $\mathrm{H}_{2} \mathrm{O}_{2}$ is around $0.06 \mathrm{mM}$ and $0.02 \mathrm{mM}$ in the absence and in presence of bromide ions, respectively. These values are quite low, but it should be borne in mind that the reactor was not optimized for catalytic performance. Nevertheless, these outcomes are in agreement with the literature, showing that bromide ions as the selectivity enhancers produce a significant decrease of the catalytic activity [12,13].

The results of the analysis of the EXAFS measurements collected under different experimental conditions at room temperature are summarized in Table 1. In Fig. 1, EXAFS signals from the as prepared catalysts (a) and after the treatment with $1.0 \mathrm{ml} / \mathrm{min}$ methanol for $2 \mathrm{~h}$ (b) are reported with their best fit curves, as an example. The contributions to the total EXAFS from the metal and oxidized (PdO) Pd phases are also shown (lower part of each panel).

In the as-prepared catalyst we found both metal Pd and PdO. After some preliminary tests, the metal phase was assumed to have the fcc structure. The interatomic distances of metal Pd are constrained to the fcc structure, leaving only the fcc edge $\left(a_{\mathrm{Pd}}\right)$ as free parameter in the refinement [44]. The $a_{\mathrm{Pd}}=3.88(1) \AA$ is in good agreement with the literature value $\left(a_{\mathrm{Pd}}=3.89 \AA\right)$ for bulk $\mathrm{Pd}$. The oxide phase $(\mathrm{PdO})$ was included with signals from two 
Table 1

Pd K-edge EXAFS data analysis results for the catalyst Pd/K2621f under different experimental conditions (in situ results in shadowed lines).

\begin{tabular}{|c|c|c|c|c|c|c|}
\hline & \multirow[t]{2}{*}{$t(\mathrm{~h})$} & \multicolumn{2}{|l|}{ Pd } & \multicolumn{2}{|l|}{ PdO } & \multirow{2}{*}{$\begin{array}{l}\text { Least square } \\
R_{\mathrm{w}}^{2} \mathrm{~g}\end{array}$} \\
\hline & & Atom \% & $a(\AA)^{\mathrm{e}}$ & $R_{\mathrm{Pd}-\mathrm{O}}(\AA)^{\mathrm{f}}$ & $R_{\text {Pd-Pd }}(\AA)^{\mathrm{f}}$ & \\
\hline Dry, as prepared ${ }^{\mathrm{a}}$ & - & $62(3)$ & $3.88(1)$ & $2.01(1)$ & $3.06(1)$ & $5.93 \times 10^{-2}$ \\
\hline Flowing methanol $^{\mathrm{b}}$ & $2+0.75$ & $64(3)$ & $3.86(1)$ & $1.99(1)$ & $3.04(1)$ & 0.137 \\
\hline Unpromoted Reaction $^{c}$ & $2.25-3$ & $65(3)$ & $3.86(1)$ & $2.05(1)$ & $2.98(1)$ & $6.12 \times 10^{-2}$ \\
\hline Promoted Reaction ${ }^{\mathrm{d}}$ & $2.25-3$ & $76(4)$ & $3.86(1)$ & $2.06(1)$ & $2.97(1)$ & $7.87 \times 10^{-2}$ \\
\hline
\end{tabular}

a Polyvinylpirrolydone pellet.

b Flow rate $1.0 \mathrm{ml} / \mathrm{min}$.

c Flow rates (ml/min): 1 (methanol), $1.72\left(\mathrm{CO}_{2}\right), \mathrm{O}_{2} \quad 0.20, \mathrm{H}_{2} 0.08$.

d The same as $\mathrm{c}+10 \mathrm{ppm} \mathrm{NaBr}$ dissolved in methanol.

e Bulk Pd lattice parameter.

${ }^{f} \mathrm{Pd}-\mathrm{O}$ and $\mathrm{Pd}-\mathrm{Pd}$ are the first and the next neighbour shells of the PdO phase.

g Quantifies the best fit quality [28].

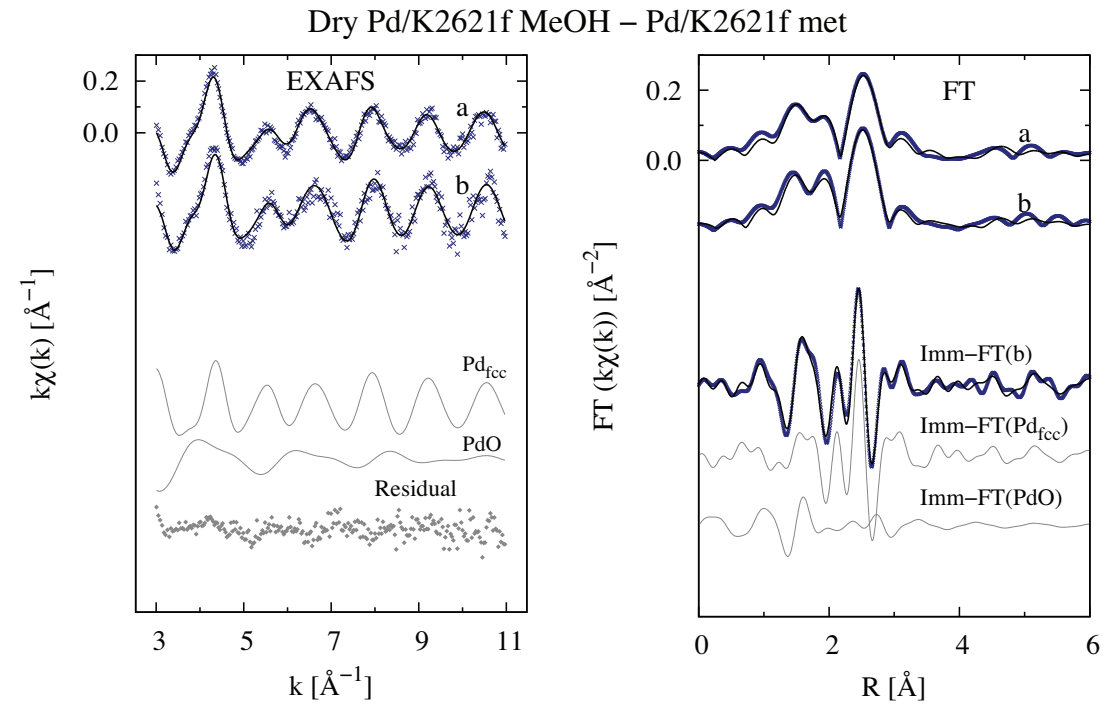

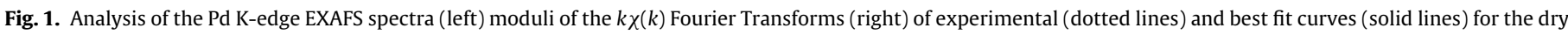

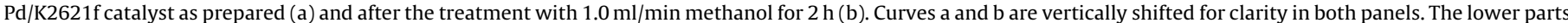

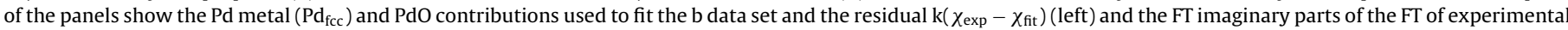

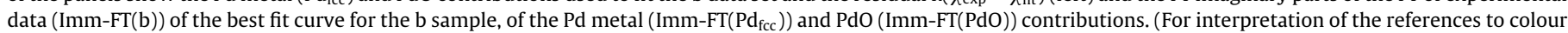
in this figure legend, the reader is referred to the web version of this article.)

coordination shells, with 4 nearest neighbours oxygen atoms at about 2 and with 4 nearest neighbours palladium atoms at about $3 \AA$, respectively. The refined $R_{\mathrm{Pd}-\mathrm{O}}$ and $R_{\mathrm{Pd}-\mathrm{Pd}}$ distances (2.01(1), $3.06(1) \AA)$ are also in good agreement with the literature values $\left(d_{\mathrm{Pd}-\mathrm{O}}=2.023 \AA\right.$ and $d_{\mathrm{Pd}-\mathrm{Pd}}=3.043 \AA$ [45]) for bulk PdO. The fraction of Pd in the metal phase has been estimated by constraining the coordination numbers of metal Pd as $x N_{\text {bulk }}{ }^{i}$, being $N_{\text {bulk }}{ }^{i}$ the $i$ th coordination number of bulk fcc structure. The estimated proportion of Pd in the as prepared catalyst is around $62 \%$.

Swelling in methanol does not appreciably affect the catalyst. The EXAFS data obtained from the measurement on the alcoholswollen material loaded in the cell fed with $1.0 \mathrm{ml} / \mathrm{min}$ of methanol (Fig. 1b) are practically the same as those of the dry catalyst (Fig. 1a). In this case the data collection $(45 \mathrm{~min})$ was started after $2 \mathrm{~h}$ of conditioning of the catalyst with the flowing solvent. Accordingly the catalyst appears to be stable in the reaction solvent.

No appreciable changes were observed when the reagents $\left(\mathrm{H}_{2}\right.$ and $\mathrm{O}_{2}$, diluted with $\mathrm{CO}_{2} ; \mathrm{CO}_{2} / \mathrm{O}_{2} / \mathrm{H}_{2}=1.72 / 0.20 / 0.08 \mathrm{ml} / \mathrm{min}$ ) were fed with methanol $(1.0 \mathrm{ml} / \mathrm{min})$. In this case the collection of the EXAFS data (lasting $\sim 45 \mathrm{~min}$ ) was started after $2.25 \mathrm{~h}$ of reaction. Under these conditions the liquid phase collected at the cell outlet turned yellow upon addition of an acidic solution of $\mathrm{TiOSO}_{4}$. indicating the formation of $\mathrm{H}_{2} \mathrm{O}_{2}$, i.e. that the catalyst is active. These findings indicate that with this experimental set-up the catalyst does not undergo any change or, most likely, that the changes are too small to be detected.

By contrast, when $10 \mathrm{ppm}$ of $\mathrm{NaBr}$ were dissolved in methanol flow we observed an appreciable increase of the atomic percentage of metal palladium and lowering of the edge jump to 0.66 from the initial value of 0.73 . These outcome clearly demonstrate that bromide ions have at least two effects: on the one hand they reduce the oxidation state of palladium and, on the other one, they promote palladium leaching. This is in agreement with the results obtained with the same catalyst in a batch-wise reactor under conditions more relevant to practical exploitation of the reaction [46]. It is possible that these effects are connected with the role of bromide ions as promoters of the DS reaction.

\section{Conclusion}

The results obtained in this work show that our in situ approach to the EXAFS characterization of heterogeneous catalysts for the DS reaction can provide useful information on the evolution of the catalyst under duty. Although the apparatus employed was not optimized for catalytic performance, the preliminary results reported herein support the hypothesis that bromide ions in low concentration ( $10 \mathrm{ppm})$, at which they are known to act as effective promoters, favour the reduction of the catalyst (increase 
of the atomic fraction of metal Pd) and the metal leaching. This is in line with other findings which were obtained in a completely independent investigation of ours on the DS reaction, suggesting that these effects are connected with the ability of bromides (and chlorides) to enhance the selectivity towards $\mathrm{H}_{2} \mathrm{O}_{2}$ of the DS catalysts.

\section{Acknowledgments}

We acknowledge $\mathrm{N}$. Novello, L. Olivi (XAFS beamline at Elettra-Sincrotrone Trieste S.C.p.A., Italy, Elettra proposal number: 20110243) and A. Rizzo (BM08 beamline at ESRF, France, ESRF proposal number: $\mathrm{CH} 3388$ ) for the support during the XAFS measurements.

\section{References}

[1] G. Blanco-Brieva, E. Cano-Serrano, J.M. Campos-Martin, J.L.G. Fierro, Chem. Commun. (2004) 1184-1185.

[2] C. Burato, P. Centomo, M. Rizzoli, A. Biffis, S. Campestrini, B. Corain, Adv. Synth. Catal. 348 (2006) 255-259.

[3] C. Burato, S. Campestrini, Y.-F. Han, P. Canton, P. Centomo, P. Canu, B. Corain, Appl. Catal. Gen. 358 (2009) 224-231.

[4] S. Sterchele, P. Biasi, P. Centomo, P. Canton, S. Campestrini, T. Salmi, M. Zecca, Appl. Catal. Gen. 468 (2013) 160-174.

[5] S. Sterchele, P. Biasi, P. Centomo, S. Campestrini, A. Shchukarev, A.-R. Rautio, J.-P. Mikkola, T. Salmi, M. Zecca, Catal. Today (2014), http://dx.doi.org/10. 1016/j.cattod.2014.02.021.

[6] B.Zhou, M. Rueter, L.-K. Lee, B. Pelrine, Utilizing an active supported noble metal phase-controlled catalyst in a liquid medium containing an organic solvent and water for providing high activity and product selectivity to the process US20020106320 A1, 2002.

[7] D.A. Rino, D.A. Giordano, P. Giuseppe, Direct synthesis of hydrogen peroxide in a multicomponent solvent system WO2002092501 A1, 2002.

[8] G. Paparatto, R. D'Aloisio, G.D. Alberti, R. Buzzoni, Process for the direct synthesis of hydrogen peroxide US6630118 B2, 2003.

[9] R. D’Aloisio, G.D. Alberti, G. Paparatto, From hydrogen and oxygen in halogenated or acid promoters and heterogeneity catalyst US20040151659 A1, 2004.

[10] H. Thomas, J. Robert, S. Guido, Process for the direct synthesis of hydrogen peroxide WO2005108285 A1, 2005

[11] T. Haas, G. Stochniol, R. Jahn, Process for the direct synthesis of hydrogen peroxide US7241908 B2, 2007.

[12] J.M. Campos-Martin, G. Blanco-Brieva, J.L.G. Fierro, Angew. Chem. Int. Ed. 45 (2006) 6962-6984.

[13] C. Samanta, Appl. Catal. Gen. 350 (2008) 133-149.

[14] J.K. Edwards, G.J. Hutchings, Angew. Chem. Int. Ed. 47 (2008) 9192-9198.

[15] J.K. Edwards, B.E.N.N. Solsona, A.F. Carley, A.A. Herzing, C.J. Kiely, G.J. Hutchings, Science 323 (2009) 1037-1041.
[16] P. Landon, P.J. Collier, A.F. Carley, D. Chadwick, A.J. Papworth, A. Burrows, C.J. Kiely, G.J. Hutchings, Phys. Chem. Chem. Phys. 5 (2003) 1917-1923.

[17] P.J. Miedziak, S.A. Kondrat, N. Sajjad, G.M. King, M. Douthwaite, G. Shaw, G.L. Brett, J.K. Edwards, J.D. Morgan, G. Hussain, G.J. Hutchings, Catal. Sci. Technol. (2013).

[18] Y.-F. Han, J.H. Lunsford, J. Catal. 230 (2005) 313-316.

[19] Q. Liu, J.C. Bauer, R.E. Schaak, J.H. Lunsford, Angew. Chem. Int. Ed. 47 (2008) 6221-6224.

[20] S. Abate, M. Freni, R. Arrigo, M.E. Schuster, S. Perathoner, G. Centi, ChemCatChem 5 (2013) 1899-1905

[21] S. Abate, R. Arrigo, M.E. Schuster, S. Perathoner, G. Centi, A. Villa, D. Su, R. Schlögl, Catal. Today 157 (2010) 280-285.

[22] S. Abate, P. Lanzafame, S. Perathoner, G. Centi, Catal. Today 169 (2011) 167-174.

[23] S. Melada, R. Rioda, F. Menegazzo, F. Pinna, G. Strukul, J. Catal. 239 (2006) 422-430.

[24] P. Biasi, J. García-Serna, A. Bittante, T. Salmi, Green Chem. 15 (2013) $2502-2513$

[25] E.N. Ntainjua, M. Piccinini, J.C. Pritchard, Q. He, J.K. Edwards, A.F. Carley, J.A Moulijn, C.J. Kiely, G.J. Hutchings, ChemCatChem 1 (2009) 479-484.

[26] T. Deguchi, M. Iwamoto, J. Phys. Chem. C 117 (2013) 18540-18548.

[27] G.A. Somorjai, C. Aliaga, Langmuir 26 (2010) 16190-16203.

[28] P. Centomo, C. Meneghini, M. Zecca, Rev. Sci. Instrum. 84 (2013) 054102.

[29] D.C. Koningsberger, R. Prins, X-ray Absorption: Principles, Applications, Techniques of EXAFS, SEXAFS and XANES, Wiley, New York, 1988.

[30] G. Bunker, Introduction to XAFS, Cambridge University Press, Berlin, 2010

[31] J.J. Rehr, R.C. Albers, Rev. Mod. Phys. 72 (2000) 621-654.

[32] B.-K. Teo, EXAFS: Basic Principles and Data Analysis, Springer, Berlin, 1986

[33] A. Filipponi, A. Di Cicco, C.R. Natoli, Phys. Rev. B 52 (1995) 15122-15148.

[34] M. Králik, B. Corain, M. Zecca, Chem. Pap. (2000) 254-264

[35] D. Gašparovičová, M. Kralik, M. Hronec, A. Biffis, M. Zecca, B. Corain, J. Mol Catal. A: Chem. 244 (1-2) (2006) 258-266.

[36] P. Centomo, M. Zecca, B. Corain, J. Clust. Sci. 18 (2007) 947-962.

[37] B. Corain, M. Zecca, P. Canton, P. Centomo, Philos. Trans. R. Soc. Math. Phys. Eng Sci. 368 (2010) 1495-1507.

[38] M. Bortolus, P. Centomo, M. Zecca, A. Sassi, K. Jeřábek, A.L. Maniero, B. Corain, Chem. Eur. J. 18 (2012) 4706-4713.

[39] A.D. Cicco, G. Aquilanti, M. Minicucci, E. Principi, N. Novello, A. Cognigni, L. Olivi, J. Phys. Conf. Ser. 190 (2009) 012043.

[40] S. Pascarelli, F. Boscherini, F. d' Acapito, J. Hrdy, C. Meneghini, S. Mobilio, J. Synchrotron Radiat. 3 (1996) 147-155.

[41] C. Meneghini, F. Bardelli, S. Mobilio, Nucl. Instrum. Methods Phys. Res. Sect. B: Beam Interact. Mater. At. 285 (2012) 153-157.

[42] V. Schröder, B. Emonts, H. Janßen, H.-P. Schulze, Chem. Eng. Technol. 27 (2004) $847-851$.

[43] I.R. Cohen, T.C. Purcell, A.P. Altshuller, Environ. Sci. Technol. 1 (1967) 247-252.

[44] C. Battocchio, C. Meneghini, I. Fratoddi, I. Venditti, M.V. Russo, G. Aquilanti, C. Maurizio, F. Biondino, R. Matassa, M. Rossi, S. Mobilio, G. Polzonetti, J. Phys. Chem. C 116 (2012) 19571-19578.

[45] J. Waser, H.A. Levy, S.W. Peterson, Acta Crystallogr. 6 (1953) 661-663.

[46] S. Sterchele, P. Biasi, N. Gemo, A. Shchukarev, A.-R. Rautio, J.-P. Mikkola, P. Canu, P. Centomo, K. Kordas, T. Salmi, unpublished results. 